\title{
Case design and climate control: a typological analysis
}

May Cassar

Born in Malta in 1955. B.A. (Hons.) in history, University of Malta, 1976. B.Sc in atchaeological conservation, London Institute of Archaeology, 1982. Unesco research fellow at ICCROM, Rome, 1982/83. Now assistant keeper (conservation), Sainsbury Centre for Visual Arts, University of East Anglia, Norwich, United Kingdom. Has published several articles in professional and scientific journals.
Type 1

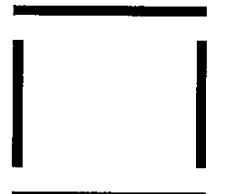

Type 2

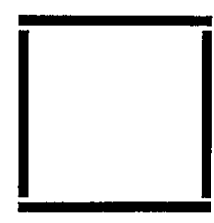

Type 3

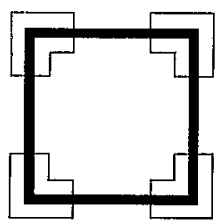

Type 4

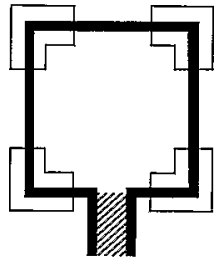

Display cases have two obvious main functions: security and protection against dust. One function which is less evident but equally important, however, is the control of the stability of relative humidity.

The climate within show-cases can be modified in two main ways. The first depends on a source of electric current and includes air-conditioners, humidifiers and dehumidifiers. These are all termed 'active' systems. The second method depends on the capacity of buffering materials such as wood, paper, textiles and silica gel to slow down the change in relative humidity. The use of humidity buffers is a 'passive' method of climate modification.

It is clear that the less exchange of air occurs between the interior and exterior of a display case, the less outside climatic conditions will affect those within the case. At present many articles describing the characteristics of display cases use terms such as 'ventilated', 'sealed' and 'airtight' without explaining their meaning.

To establish a common ground for future discussion, this paper proposes typologies for display-case designs and various active and passive systems of climate control. The typologies, when combined, can be used to classify different methods used to modify the climate within display cases.

This analysis and its diagrammatic representation refer to the control of relative humidity (RH) only, even though the control of temperature fluctuations and of both gaseous as well as particulate forms of pollution and dust are also of vital importance to the control of relative humidity. Furthermore, this scheme concentrates on a discussion of construction methods which reduce to a minimum leakage of air from the case. The typology of case designs therefore emphasizes 'impermeable' construction materials to promote $\mathrm{RH}$ control, of particular importance for artefacts made of organic materials. For certain metallic artefacts, however, this does not apply, and an adequate ventilation rate, rather than a minimal exchange of air between the inside and the outside of the case, may be more desirable to dissipate harmful vapours which will cause metallic artefacts to deteriorate. Although these typologies of case construction and climate-control systems focus on the importance of stabilizing $\mathrm{RH}$ variations, a clear distinction should be made between the priorities for the display of organic materials and those for metals.

\section{Basic display case construction designs in current use}

The following four basic types of display cases in current use in museums have been extrapolated from publications of experiments:

Type 1

Description: case in which there is free air exchange between the inside of the case and ambient gallery conditions.

Example: commercially available standard stock in which no attempt has been made to lessen air exchange.

Materials: the frame is made of either metal or wood. In older cases, wood is the more likely material, painted or unpainted. The panes are more commonly made of glass, and would be in either doors on hinges with an ordinary lock for security, or in sliding-door type with a gap between the panes. Most museum display cases fall within this category.

Advantage: protects against theft and vandalism.

Disadvantages: does not modify adverse ambient environmental conditions. The climate inside the case will reflect, with a minimum time-lag, depending on the buffering capacity of the materials of the case itself, the climate surrounding it. It allows the free passage not only of air, but also of dust, dirt and pollutants.

\section{Type 2}

Description: case in which a reduction of the exchange of air between the interior and exterior climate has been achieved. 
Example: commercially available or custom-built stock in which a conscious effort has been made to have a wellconstructed case that better isolates the interior environment.

Materials: the frame is made of painted or varnished wood, or metal. The panes are made either of glass or perspex, bearing in mind the diffusion capacity of this material. The number of joins are kept to a minimum to avoid air leakage, and where they are necessary, between the panes and the frame, sealants are used to minimize air exchange.

Advantages: may be used to create a microclimate for the object, that is, a more stable climate than prevails outside the case. It protects against the entry of dust and pollution in particulate form. It can be undertaken without incurring too much expense and without it becoming labour-intensive.

Disadvantages: through the reduction of air-exchange between the inside of the case and its ambience, there may be a build-up of acid vapours as breakdown products of degrading materials within the case. Unless these vapours are dispersed, they will cause the object to deteriorate.

\section{Type 3}

Description: case in which an attempt has been made to reduce air leakage to a minimum.

Example: owing to considerable cost in time and money, standard airtight museum cases do not exist. Since there will always be some diffusion through porous construction materials or through joins, this represents the type of case in which the air-exchange rate has been consciously reduced to a minimum. Cases described as 'hermetically sealed' in the literature, fall into this category.

Materials: every material is made of impermeable fabric such as metal for the frame and glass for the panes. The joins and closures are either fused, soldered or welded together permanently using such materials as lead solder. The case may contain either air or an inert gas. The possible inclusion of a leak detector would be evidence that the case is not airtight.

Advantages: protects against fluctuating $\mathrm{RH}$ by isolating the object within a microclimate within the case. It provides also the surest protection against the effects of dust, dirt, pollution and microorganisms.

Disadvantages: high cost in terms of time and money. It is therefore feasible only for individual and unique wotks of art. This type is more applicable to $\mathrm{RH}$ control for organic objects rather than for the display of vulnerable metals. The entry of small amounts of air may cause deterioration of materials, the acid breakdown products of which, finding no escape, will accumulate within the case and cause the degradation of the object. It should be stated that although attempts had been made in the past to use such cases under vacuum, it is difficult to maintain this, even over a short period of time, and it has never actually been achieved with a museum case.

\section{Type 4}

Description: case into which air is allowed to enter through one source, usually a hole into which a filter has been placed.

Example: owing to the conscious decision to allow air-exchange between the interior and exterior of the case through one source, leakage of air through joins or porous construction materials is minimized. However, every effort should be made to construct a case similar to Type 3.

Materials: similar materials to the case described in Type 3 are used, including the fact that a hole, the diameter of which has been quoted differently by different authors, is constructed. A filter placed inside the hole to eliminate dust and sulphur dioxide allows only pure air to enter the case.

Advantages: does not allow the entry into the case of corrosive vapours which could harm the object.

Disadvantages: deliberate leakage must be taken into account when a microclimate is being set up, and allowance made for the change it may cause. Consequently it may complicate calculations of quantities of buffering materials. It may prevent entry of corrosive vapours, but it does nothing to actively dispel those vapours that have accumulated in the case from the materials used. It may be labour-intensive and expensive to construct.
In concluding this typology of basic display case construction designs, it can be stated that, for Type 1 , the climate inside and outside the case would, at any one time, be similar. As regards Types 2, 3 and 4 , however, the establishment of microclimates in these cases seems to be more feasible than in Type 1 . Taking into consideration such variables as ambient conditions, case materials, quantity of buffering agent and mass of object, the length of the life of the mictoclimate may be extended depending on the requirements of the display.

\section{Controlled climate systems for display cases in museums}

The macroclimatic and microclimatic systems described below have also been extracted from the literature and exemplify the more sought-after trends for the control of the environment within a display case:

\section{Macroclimate: mechanical systems}

\section{System I.A}

Description: air-conditioning plant to control the general gallery conditions.

Advantages: this system should not only control RH and temperature, but should also filter gaseous pollutants and dirt. (Unfortunately, this is not always the case.) It is however the complete answer to environmental control.

Disadvantages: the more obvious disadvantages of this system are cost, maintenance and that it is a measure which cannot be undertaken quickly. ${ }^{1}$

\section{System I.B}

Description: air-conditioning plant which first forces conditioned air through a case before circulating it into the gallery.

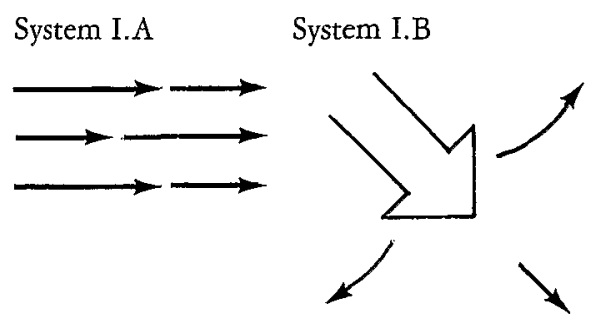

1. This system will not be covered extensively in this article, which concentrates primarily on microclimate control. 
Advantages: ensures that conditioned air goes through the case and then outwards under pressure. Dust, dirt and pollutants are unable to affect the object by entering the case. This system is better adapted for use with several wall cases.

Disadvantages: has similar cost, maintenance and lack of reliability in terms of breakdown, as System I.A. It does not allow flexibility in display layout, which however, System I.A does have.

\section{Microclimate: external control}

System II.C

Description: dehumidifier or humidifier system attached to one or a small number

System II.C

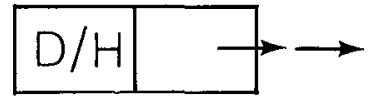

System II.D

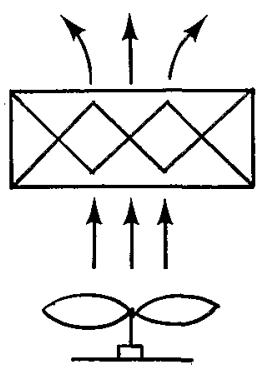

System II.E

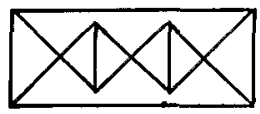

of cases to control the microclimate within the cases without affecting gallery conditions.

Advantages: can be installed quickly in case of emergency. It allows for flexible use with either one or several cases. It does not have high installation or maintenance costs.

Disadvantages: subject to breakdown as a mechanical system. It may not be sensitive enough in the RH range required.

\section{Microclimate: internal control}

\section{System II.D}

Description: dynamic buffering system, using hygroscopic materials such as silica gel or saturated salt solutions, to ballast fluctuations in humidity. This system includes a fan to circulate the conditioned air which could either have had the moisture-content increased or reduced.

Advantages: functions as an independent system within the case. This is a simple system which requires little maintenance. Inclusion of a fan prevents the formation of pockets of stagnant air within the case.

Disadvantages: breakdown of the fan may cause the malfunction of the system especially if the buffering agent has not been well distributed within the case, by causing uneven humidity levels to form.

\section{System II.E}

Description: a simplified form of System II.D.

Advantages: static system of control of humidity excludes the fan which is subject to malfunction. This is a simple and effective system of microclimate control which works independently of gallery conditions but takes them into consideration. It is inexpensive and can run itself with the minimum of attention.

Disadvantages: unless all the variables are considered carefully before installing such a static system of microclimate control, the special climate established will soon drift towards gallery conditions.

\section{Discussion}

Once the need for some form of climate control has been identified, a decision has to be made primarily between the use of either a macro- or a microclimatically controlled system. The choice depends on a number of factors such as finance, available time, urgency of the problem, size of the collection requiring attention, and the co-operation, knowledge and interest of the personnel recommending, approving and finally, undertaking the task. If microclimate control of individual casses or groups of cases is decided upon, the choice of internal or external, static or dynamic control of climate should next be considered. Consequently, it is not only misleading but also dangerous to generalize by suggesting one system in preference to another, for given sets of circumstances.

The climate systems listed above may be used either individually or in varied combination with any one of the four types of museum display cases which have also been described. The tabulation of the two typologies links these climatecontrol systems and display-case types in an effort to standardize terminology. The climate-control systems are listed in Table 1 along the vertical axis, while the different types of museum display cases are arranged along the horizontal axis. By reading along both axes, line diagrams of different climate/case combinations may be located. Each combination is illustrated by examples which have been reported after experiment, trial and use. These examples are listed opposite. Since not all methods of climate control can be effectively or even sensibly used wih every type of case construction design, only the more practical combinations have been tabulated, after a search through the literature. This does not mean that such an example has not been attempted. In fact any suggestions or information to modify or complete Table 1 would be appreciated.

\section{Examples from publications in support of Table 1}

1:A Vast majority of museums with airconditioned galleries have this type of case construction.

1:B Metropolitan Museum of Art Egyptian Galleries (Phase I). See article by Bill Barrette, p. 81 .

1:C Combination of climate and case unlikely to exist.

1:D Combination of climate and case unlikely to exist.

1:E Most museum cases in which an attempt has been made to create a microclimate without actually understanding the limitations of the system. 
2:A Large number of museums with air-conditioned galleries have this type of case construction.

2:B As presented by S. Michalski, p. 85.

2:C Museum of Mankind, The Ethnographic Department of the British Museum, London: Temporary Exhibition on Mexican Art, 1971.

2:D R. H. Organ, 'The Safe Storage of Unstable Glass', The Museum Journal, Vol. 56, Aptil 1956March 1957.

2:E B. L. Ramer, 'Stabilising RH Variations within Display Cases: The Role of Silica Gel and Case Design', in ICOM Committee for Conservation, 6th Triennial Meeting, Ottawa, 1981. See also article in this issue, p. 91.

3:A Metropolitan Museum of Art Egyptian Galleries (Phase III). See article in this issue, p. 81.

3:B Combination of climate and case unlikely to exist.

3:C British Museum cases for Unstable Metal Objects: G. Thomson, The Museum Environment, London, Butterworths, 1978.

3:D Literature or personal discussion have failed to reveal the use of this combination of climate and case.

3:E S. Miura, 'Control of Climate in a Showcase by means of Zeolite: Report on the Exhibition of "La Joconde", in ICCROM Conference on Museum Conservation Climate, Rome, 1978.

4:A Literature or personal discussion have failed to reveal the use of this combination of climate and case.

4:B Combination of climate and case unlikely to exist.

4:C Combination of climate and case unlikely to exist.

4:D Literature or personal discussion have failed to reveal the use of this combination of climate and case.

4:E Literature or personal discussion have failed to reveal the use of this combination of climate and case.

From an examination of Table 1 and the examples which support it, it can be seen that microclimate control seems to have been attempted, not surprisingly, in museum cases in which a reduction of the exchange of air between the interior and exterior climate has been achieved (Type 2). The air-conditioning of museum galleries, however, is still a common feature in museum climate control (System I.A), and a variety of cases have been used in these conditions $(1: A, 2: A$, $3: A)$. The creation of a microclimate within a case in which there is free exchange of air between the inside of the case and ambient gallery conditions (Type 1 ) is a waste of time, money and effort, yet it appears very likely that precisely this has been often attempted and is still being done. Unfortunately this shows a lack of understanding of the basic principles of microclimate control in museums.

TABLE 1. Standardizing the use of museum display cases and climate control systems:

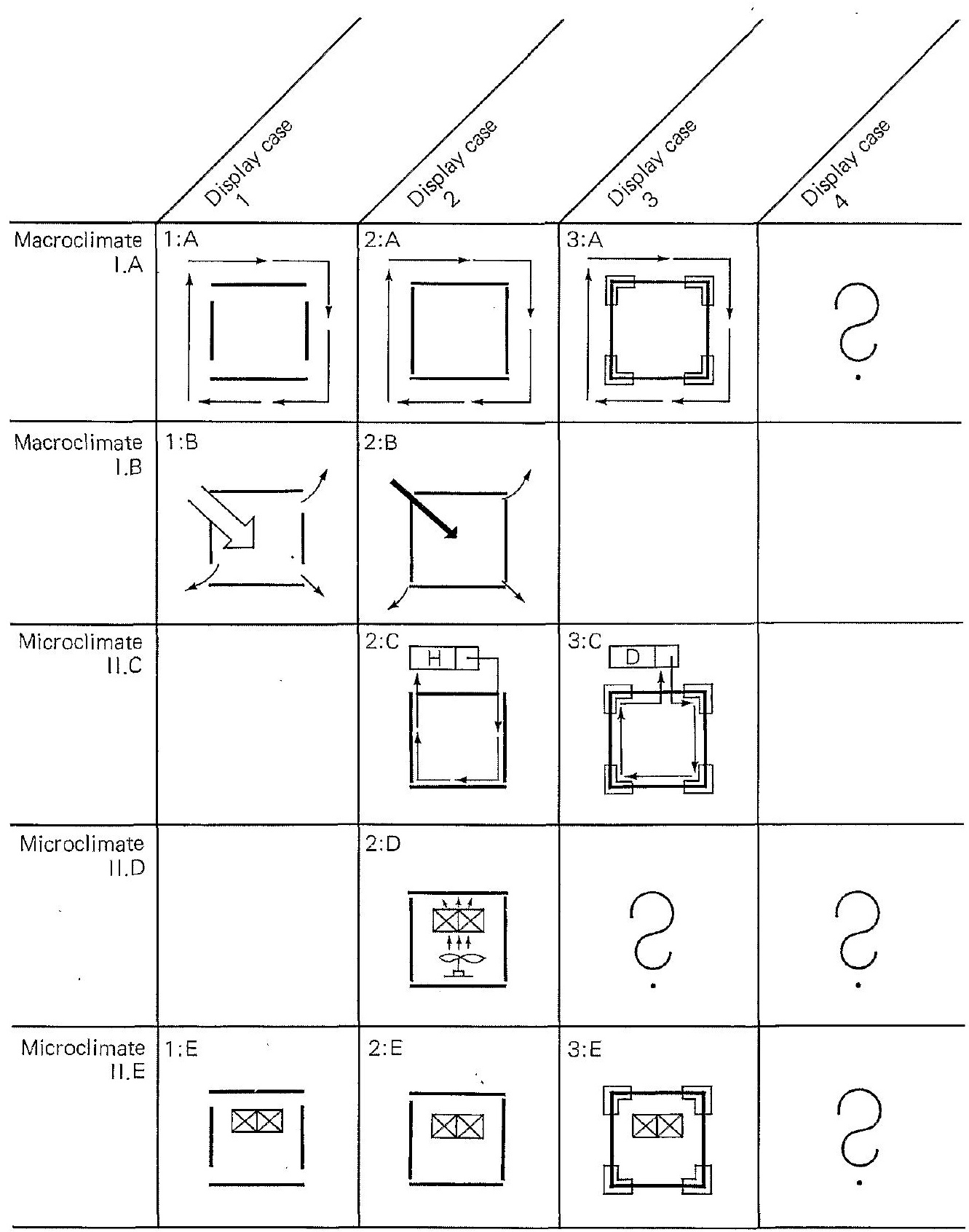

